Swarthmore College

Works

$7-1-2012$

\title{
Dietary Lipid Saturation Influences Environmental Temperature Preference But Not Resting Metabolic Rate In The Djungarian Hamster (Phodopus Sungorus)
}

Ryan Pannorfi , '04

Barry Michael Zee , '08

I. Vatnick

N. Berner

Sara Hiebert Burch

Swarthmore College, shieber1@swarthmore.edu

Follow this and additional works at: https://works.swarthmore.edu/fac-biology

Part of the Biology Commons

Let us know how access to these works benefits you

\section{Recommended Citation}

Ryan Pannorfi , '04; Barry Michael Zee, '08; I. Vatnick; N. Berner; and Sara Hiebert Burch. (2012). "Dietary Lipid Saturation Influences Environmental Temperature Preference But Not Resting Metabolic Rate In The Djungarian Hamster (Phodopus Sungorus)". Physiological And Biochemical Zoology. Volume 85, Issue 4. 405-414. DOI: $10.1086 / 666473$

https://works.swarthmore.edu/fac-biology/3

This work is brought to you for free by Swarthmore College Libraries' Works. It has been accepted for inclusion in Biology Faculty Works by an authorized administrator of Works. For more information, please contact myworks@swarthmore.edu. 


\section{CHICAGO JOURNALS}

Dietary Lipid Saturation Influences Environmental Temperature Preference but Not Resting Metabolic Rate in the Djungarian Hamster ( Phodopus sungorus)

Author(s): Ryan Pannorfi, Barry M. Zee, Itzick Vatnick, Nancy Berner, and Sara M. Hiebert

Source: Physiological and Biochemical Zoology, Vol. 85, No. 4 (July/August 2012), pp. 405-414

Published by: The University of Chicago Press

Stable URL: http://www.jstor.org/stable/10.1086/666473

Accessed: 05/03/2014 14:48

Your use of the JSTOR archive indicates your acceptance of the Terms \& Conditions of Use, available at http://www.jstor.org/page/info/about/policies/terms.jsp

JSTOR is a not-for-profit service that helps scholars, researchers, and students discover, use, and build upon a wide range of content in a trusted digital archive. We use information technology and tools to increase productivity and facilitate new forms of scholarship. For more information about JSTOR, please contact support@jstor.org. 


\section{Dietary Lipid Saturation Influences Environmental Temperature Preference but Not Resting Metabolic Rate in the Djungarian Hamster (Phodopus sungorus)}

\author{
Ryan Pannorfi ${ }^{1}$ \\ Barry M. Zee ${ }^{1}$ \\ Itzick Vatnick ${ }^{2}$ \\ Nancy Berner ${ }^{3}$ \\ Sara M. Hiebert ${ }^{1, \star}$ \\ ${ }^{1}$ Department of Biology, Swarthmore College, Swarthmore, \\ Pennsylvania 19081; ${ }^{2}$ Department of Biology, Widener \\ University, Chester, Pennsylvania 19013; ${ }^{3}$ Department of \\ Biology, University of the South, Sewanee, Tennessee 37383
}

Accepted 4/20/2012; Electronically Published 6/8/2012

\begin{abstract}
Heterothermic rodents increase self-selection of diets rich in polyunsaturated fatty acids (PUFAs) when exposed to cold, short days, or short-day melatonin profiles, and Djungarian hamsters (Phodopus sungorus) do so in long days in response to cold exposure alone. To determine whether Djungarian hamsters are also capable of selecting a thermal environment in response to dietary lipid composition, continuously normothermic hamsters were fed either a PUFA-rich diet or a diet rich in saturated fatty acids (SFAs) for 6-10 wk and given a choice of thermal environments. As predicted, SFA-fed hamsters were more likely than PUFA-fed hamsters to occupy the single heated corner of their cage $(P=0.0005)$ and were most likely to show this diet-related difference in behavior when $T_{\mathrm{a}}$ fell within the thermal neutral zone. Respirometry revealed no effect of diet on whole-animal or mass-specific resting metabolic rate or on lower critical temperature. The results are more consistent with the homeoviscous adaptation hypothesis, which predicts that organisms should make physiological and/or behavioral adjustments that preserve membrane fluidity within a relatively small range, than with the membrane pacemaker hypothesis, which predicts that high PUFA content in membrane phospholipids should increase basal metabolic rate.
\end{abstract}

*Corresponding author; e-mail: shieber1@swarthmore.edu.

Physiological and Biochemical Zoology 85(4):405-414. 2012. (C) 2012 by The University of Chicago. All rights reserved. 1522-2152/2012/8504-1018 $\$ 15.00$. DOI: $10.1086 / 666473$

\section{Introduction}

The composition of dietary lipids affects physiological performance and is important in the etiology of aging, neurological susceptibility to hypoxia, cancer, and cardiovascular and inflammatory disease (Dauncey and Bicknell 1999; Wood et al. 2009; Cole et al. 2010; Kariyazono and Nakamura 2010; MacLennan and Ma 2010). Among biologists studying mammalian heterothermy (i.e., hibernation and daily torpor), one of the major foci of dietary lipid research has been to elucidate the relation between dietary lipids and the physiological characteristics of torpor, including minimum body temperature during torpor, duration of torpor bouts, and metabolic rate during torpor. Broadly speaking, the results of experiments on mammalian heterotherms have shown that mammals fed diets high in polyunsaturated fatty acids (PUFAs) typically experience at least some of the following effects on torpor: increased torpor bout duration, decreased minimum body temperature $\left(T_{\mathrm{b}}\right)$, and lower metabolic rate during torpor, relative to conspecifics fed a diet high in saturated fatty acids (SFAs; reviewed by Munro and Thomas 2004). Studies of ectotherms, which may also experience large changes in body temperature, show a similar effect: animals fed a diet high in unsaturated fats (UFAs; including monounsaturated and polyunsaturated fatty acids) behaviorally select a lower $T_{\mathrm{b}}$ than do conspecifics fed a diet high in SFAs (Geiser and Learmonth 1994; Simandle et al. 2001).

Several hypotheses have been advanced to explain these findings. The most commonly invoked is the homeoviscous adaptation (HVA) hypothesis (Sinensky 1974; Hazel 1995), which postulates (1) that the overall fluidity of lipid bilayers must be maintained in a particular range if the membrane as a whole is to maintain function and (2) that increasing the proportion of phospholipids containing unsaturated fatty acyl chains decreases phospholipid packing and thereby increases the fluidity of the membrane. Organisms may also benefit from homeoviscous adaptation in depot lipids, which store fatty acids in the form of triglycerides. It is widely believed, for example, that lipids must be fluid to be metabolically accessible (Irving et al. 1957; Aloia 1988; Frank and Storey 1995; Gunstone 1996).

A second more general hypothesis argues that membrane phase, rather than membrane fluidity per se, is the primary membrane feature that needs to be preserved as temperature changes (Williams 1998). Homeophasic adaptation (HPA) may play a role in maintaining the ability of membranes to fuse or form vesicles, which are functions that are important in regulating the transit of metabolic substrates, signal molecules, and other materials between the cell and its environment. 
A third, non-mutually exclusive hypothesis that also predicts increased incorporation of unsaturated fatty acids into cell membranes during cold exposure has been proposed by Hulbert and Else (1999) and supported by the work of Brand and coworkers (Porter et al. 1996; Brookes et al. 1998; Brand et al. 2003). Their membrane pacemaker hypothesis focuses on the leakiness imparted to membranes by loosely packed phospholipids. According to this hypothesis, endotherms in cold environments could increase heat production by incorporating higher proportions of unsaturated fatty acyl chains into membrane phospholipids, which results in increased ion leak across these membranes. Greater ion leak in turn increases membrane pump activity to maintain physiologically favorable ion gradients and liberates extra metabolic heat as a by-product of increased pumping activity. The increased heat production could be used by normothermic and torpid endotherms to maintain steady state body temperature in environments colder than their body temperature set points as well as by heterotherms to warm up during arousal from the torpid state.

Previous experimental paradigms have addressed the predictions of the HVA model by investigating the effects of diets high in saturated or unsaturated lipids on thermoregulation and metabolism in a variety of mammalian heterotherms, based on the demonstrated ability of dietary lipid composition to influence the lipid composition of somatic triglycerides (Thorp et al. 1994), membrane phospholipids, and membrane function in both homeotherms and heterotherms (McMurchie 1988; Field et al. 1990; Charnock et al. 1992; Ayre and Hulbert 1996; Summers et al. 2000; Hulbert et al. 2005). Our approach has been to investigate behavioral diet choice in response to changes in ambient temperature (Hiebert et al. 2000, 2003). These studies have demonstrated that Phodopus express ambient-temperature-dependent dietary lipid choice and that their preference for a diet rich in unsaturated fatty acids increases as ambient temperature decreases even in the absence of the large changes in core body temperature that would accompany bouts of daily torpor.

In this study, we invert this paradigm to further investigate the relation between the saturation of dietary lipids and thermally relevant behavior: whereas previous experiments have asked whether $T_{\mathrm{a}}$ affects dietary lipid choice, we now ask whether the saturation of dietary lipids influences the choice of thermal environment. Previous studies have investigated choice of thermal microclimate in small mammals (e.g., Gaskill et al. 2009; Terrien et al. 2010; reviewed in Terrien et al. 2011), but none of these studies addressed the question of whether dietary lipid composition might affect such choice. The three hypotheses described above predict that hamsters fed a diet high in SFAs should have an increased preference for a warm environment relative to hamsters fed a diet high in PUFAs, because the reduced fluidity and heat production of highly saturated membranes would be counteracted by exposure to a higher temperature. To determine whether lipid saturation of the diet might exert its effects on thermal preference by affecting resting metabolic rate or by altering the range of temperatures that fall within the thermal neutral zone (TNZ), we also mea- sured rates of oxygen consumption in each diet treatment group at a range of $T_{\mathrm{a}}$ 's $\left(\sim 5^{\circ}\right.$ to $\left.\sim 31^{\circ} \mathrm{C}\right)$ both below and within the TNZ for this species (Heldmaier and Steinlechner 1981).

\section{Material and Methods}

Animals

All procedures used in this study conform to the practices set forth in the Guide for the Care and Use of Laboratory Animals (National Research Council 1996) and were approved by the Institutional Animal Care and Use Committee at Swarthmore College (protocol 02-9-6-1) and Widener University (protocol 03-009). Twenty hamsters of both sexes, bred at Swarthmore College from stock originating in the laboratory of Irving Zucker at the University of California, Berkeley, were used for this study. Hamsters were reared from birth at an ambient temperature of $22^{\circ} \pm 2^{\circ} \mathrm{C}$ under a long-day photoperiod of $14 \mathrm{~L}: 10 \mathrm{D}$ (lights on at 0700 hours) and were maintained under this photoperiod throughout both experiments described below. From weaning, animals were housed individually in plastic cages $(18 \mathrm{~cm} \times 28 \mathrm{~cm} \times 13 \mathrm{~cm})$ lined with pine shavings and provided ad lib. access to food (Purina 5001, 4.5\% crude fat) and water. Djungarian hamsters maintained in these conditions are continuously normothermic (Steinlechner et al. 1986; Ruby and Zucker 1992).

\section{Experiment Design and Data Analysis}

Experiment 1: Effect of Dietary Lipid on Temperature Choice. At the beginning of the study, hamsters were moved to a walk-in environmental chamber and divided into two groups $(N=$ 10 in each) balanced for mean and distribution of body mass, age, sex, and parentage. One group (SAT) was randomly assigned to the SFA-rich diet; the other group (UNSAT) was assigned to the PUFA-rich diet. SAT and UNSAT hamsters were given ad lib. access to their respective experimental diets (see below for details) for $6 \mathrm{wk}$ before thermal choice trials began and during the subsequent $4 \mathrm{wk}$ while thermal choice experiments were being performed. Cages were arranged on cage racks so that equal numbers of hamsters in each treatment group were housed on each shelf.

During thermal choice trials, four cages (two housing SAT hamsters and two housing UNSAT hamsters) were arranged such that one corner of each cage was placed over an underaquarium heating pad, the heat output of which was regulated by a manually operated rheostat (fig. 1). Air temperatures were varied from night to night within a range of $24^{\circ}-29^{\circ} \mathrm{C}$. These temperatures were selected because they lie within the TNZ of Phodopus (Heldmaier and Steinlechner 1981). At air temperatures below its TNZ, each hamster would be expected to prefer the warmest location regardless of diet. Thus, we reasoned that temperatures close to and within the lower range of the TNZ should provide the best indication that the thermal choices of the two diet treatment groups are due to considerations other than the metabolic cost of maintaining a constant core body temperature. 

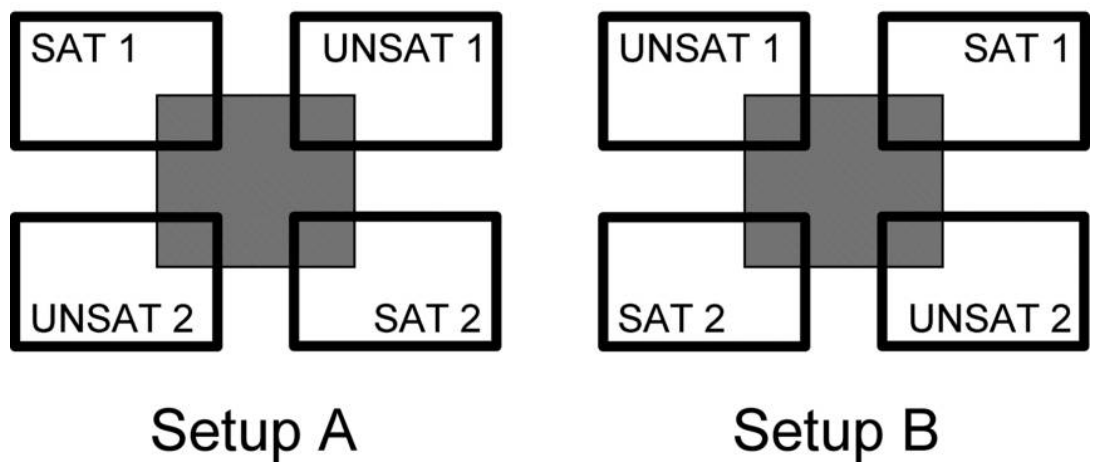

Figure 1. Experiment 1: arrangement of cages containing hamsters that had been fed a diet rich in unsaturated fatty acids (UNSAT) or in saturated fatty acids (SAT). An underaquarium heater (center shaded square) heated one corner of each cage an average of $2.7^{\circ} \mathrm{C}$ above the temperature of the unheated corners. After scoring which corner was occupied by a sleeping hamster each morning, each cage was replaced with a clean cage containing fresh bedding, and hamsters were moved from setup A to setup B or vice versa to control for the use of landmarks in choosing a sleeping corner.

On a total of 26 mornings, $2-3 \mathrm{~h}$ after lights-on, we visually determined the location of each hamster and whether this location was heated or unheated. Hamsters in our colony almost always sleep in one of the corners of the cage and, because they are nocturnal, have usually selected this sleeping location before or around the time of lights-on. To determine the temperature of the floor in each corner of the cage without disturbing sleeping hamsters, floor temperature was measured with a type $\mathrm{T}$ (copper-constantan) thermocouple connected to a handheld microprocessor (Omega $\mathrm{HH} 23 \mathrm{~A}$, display resolution $0.1^{\circ} \mathrm{C}$ with $0.1 \%$ reading accuracy) in five identical but unoccupied cages, each positioned in one of the four-cage assemblies on each shelf of the cage rack.

After the animals had been scored for sleeping location each day, each hamster was provided with a freshly washed cage with fresh bedding to eliminate the possibility that hamsters chose sleeping locations based on preference for a previously occupied corner that could be identified by scent. At cage changing, the position of each hamster's cage in the four-cage assembly was also moved and rotated, to remove familiarity with landmarks or other spatial information (Deutschlander et al. 2003) within or outside the cage as a criterion for choosing a sleeping corner (fig. 1).

Experiment 2: Effect of Dietary Lipid on Metabolic Rate. At the conclusion of experiment 1 , animals were returned to colony housing at $22^{\circ} \pm 2{ }^{\circ} \mathrm{C}$ and continued to feed ad lib. on their respective experimental diets. Beginning in week 24, the rate of oxygen consumption was measured at temperatures ranging from $5^{\circ}$ to $31^{\circ} \mathrm{C}$ for each hamster (see below for respirometry details). Each hamster was measured in two sessions, once at temperatures below the $\mathrm{TNZ}\left(5^{\circ}, 12^{\circ}\right.$, and $19^{\circ} \mathrm{C}$; cold runs) and once at ambient temperatures close to and within the TNZ $\left(24^{\circ}, 26^{\circ}, 28^{\circ}\right.$, and $31^{\circ} \mathrm{C}$; warm runs). Three hamsters could be measured on each day, with animals from the two treatment groups scheduled alternately throughout the measurement period (two SAT and one UNSAT animal on one day, one SAT and two UNSAT animals on the next day, etc.) to control for day effects. At least 1 wk elapsed between the cold and warm runs for each individual animal.

At approximately 1800 hours on the night before respirometry measurements were to be taken, food (but not water) was removed from each test hamster's cage so that metabolic rate would represent postabsorptive levels during the next day's measurements. Each hamster was weighed and placed in the respirometry chamber between 0730 and 0830 hours and remained in the chamber for $9 \mathrm{~h}$ (cold runs) or $11 \mathrm{~h}$ (warm runs) while oxygen consumption was monitored continually. To promote restful behavior during the run, respirometry chambers were darkened by covering them with dark plastic. In pilot trials, we observed that the animals spent most of this time sleeping. At the end of the run, the hamster was reweighed, returned to its home cage, and again given ad lib. access to both water and experimental diet. When returned to their home cages, most hamsters did not immediately begin eating but rather explored the cage, groomed, and drank water.

\section{Experimental Diets}

Isocaloric experimental diets consisted of rodent chow (Purina $5001,4.5 \%$ crude fat) with a $10 \%$ addition by mass of coconut oil (Sigma C1758) for the SFA-rich diet or $10 \%$ addition by mass of sunflower oil (Hain, Boulder, CO, or Loriva, Bloomfield, NJ) for the PUFA-rich diet (table 1). Diets were prepared by tossing pellets with liquid oils and heating in a convection oven at $120^{\circ} \mathrm{C}$ for approximately $30 \mathrm{~min}$ to permit added oils to permeate pellets uniformly without browning. Diets were kept at $4^{\circ} \mathrm{C}$ under nitrogen gas until fed to the animals.

\section{Respirometry}

We used flow-through gas respirometry to measure rates of oxygen consumption, which serve as a proxy for metabolic rate. Respirometry chambers consisted of custom-made double- 
Table 1: Percentage of identified fatty acid components of experimental diets

\begin{tabular}{|c|c|c|c|}
\hline Diet component & $\begin{array}{l}\text { Chain length: } \\
\text { no. double bonds }\end{array}$ & $\begin{array}{l}\text { SFA-rich diet } \\
\text { (coconut oil) }\end{array}$ & $\begin{array}{l}\text { PUFA-rich diet } \\
\text { (sunflower oil) }\end{array}$ \\
\hline Caprylic acid & $8: 0$ & $4.2 \%$ & ND \\
\hline Capric acid & $10: 0$ & $3.4 \%$ & ND \\
\hline Lauric acid & $12: 0$ & $26.8 \%$ & ND \\
\hline Myristic acid & 14:0 & $10.6 \%$ & ND \\
\hline Palmitic acid & $16: 0$ & $11.1 \%$ & $8.7 \%$ \\
\hline Palmitoleic acid & $16: 1$ & $.5 \%$ & ND \\
\hline Stearic acid & $18: 0$ & $2.9 \%$ & $3.4 \%$ \\
\hline Oleic acid & $18: 1$ & $13.4 \%$ & $44.7 \%$ \\
\hline Linoleic acid & $18: 2 n-6$ & $23.1 \%$ & $37.3 \%$ \\
\hline$\alpha$-linolenic acid & $18: 3 n-3$ & $2.7 \%$ & $2.7 \%$ \\
\hline Behenic acid & $22: 0$ & ND & $.6 \%$ \\
\hline Total trans fats & ... & ND & ND \\
\hline Total n-3 & $\ldots$ & $3.1 \%$ & $2.7 \%$ \\
\hline Total n-6 & $\ldots$ & $21.6 \%$ & $37.3 \%$ \\
\hline Total SFA & $\ldots$ & $56.2 \%$ & $13.6 \%$ \\
\hline Total MUFA & $\ldots$ & $13.3 \%$ & $45.1 \%$ \\
\hline Total PUFA & $\ldots$ & $24.6 \%$ & $40.0 \%$ \\
\hline Total UFA ${ }^{\mathrm{a}}$ & $\ldots$ & $37.9 \%$ & $85.1 \%$ \\
\hline SFA : UFA & $\cdots$ & 1.5 & .2 \\
\hline Unsaturation index $(\mathrm{UI})^{\mathrm{b}}$ & $\ldots$ & 67 & 128 \\
\hline Total C16 & ... & $10.9 \%$ & $8.8 \%$ \\
\hline Total $\mathrm{C} 18^{\mathrm{c}}$ & $\ldots$ & $39.4 \%$ & $88.1 \%$ \\
\hline Total C20 ${ }^{c}$ & $\ldots$ & $.7 \%$ & $.6 \%$ \\
\hline Total C22 ${ }^{\mathrm{c}}$ & $\ldots$ & $.4 \%$ & $.6 \%$ \\
\hline Total C24 ${ }^{\mathrm{c}}$ & $\ldots$ & $.1 \%$ & $.2 \%$ \\
\hline
\end{tabular}

Note. Fatty acids are shown if they represented $>0.5 \%$ of the total lipid content. Fatty acids representing $<0.5 \%$ are shown as not detectable (ND).

${ }^{\mathrm{a}}$ Unsaturated fatty acids (UFA) $=$ monounsaturated fatty acids (MUFA) + polyunsaturated fatty acids (PUFA).

${ }^{\mathrm{b}} \mathrm{UI}=$ the percentage composition for each fatty acid species multiplied by the number of double bonds it contains, summed for all unsaturated fatty acids in the sample. UI is a correlate of membrane fluidity (Hazel and Williams 1990).

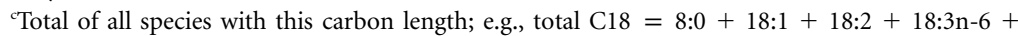
$18: 3 n-3$.

walled glass cylinders (length $=25 \mathrm{~cm}$, outer diameter $=7$ $\mathrm{cm}$, wall thickness $=0.75 \mathrm{~cm}$, inner diameter $=5.5 \mathrm{~cm}$; total volume $=\sim 590 \mathrm{~mL}$ ). Chamber temperature was controlled by continuously circulating water through the glass jacket with a Neslab RTE-211 programmable refrigerated bath and circulator. Water from the jacket of the test chamber also flowed through the jacket of an unoccupied chamber connected in series with the test chambers; a thermocouple measured $T_{\mathrm{a}}$ in the center of this unoccupied chamber to prevent hamsters from contacting the thermocouple during the run. During cold runs, water temperature circulating through the respirometer jackets was programmed to begin at $19^{\circ} \mathrm{C}$, hold each temperature $\left(19^{\circ}\right.$, $12^{\circ}$, and $5^{\circ} \mathrm{C}$, consecutively) for $160 \mathrm{~min}$, and ramp between temperatures for $20 \mathrm{~min}$. During warm runs, the water bath was programmed to begin at $24^{\circ} \mathrm{C}$, hold each temperature $\left(24^{\circ}\right.$, $26^{\circ}, 28^{\circ}$, and $31^{\circ} \mathrm{C}$, consecutively) for $160 \mathrm{~min}$, and ramp between temperatures for $5 \mathrm{~min}$. The order of test temperatures and ramping times was limited by the differential capacities of the circulator to warm and cool the bath, respectively.

A Sable Systems (Las Vegas, NV) mass flow controller regulated the flow of excurrent air at $680 \mathrm{~mL} \mathrm{~min}^{-1}$ in each of four respirometry chambers connected in parallel (three chambers with animals, one unoccupied chamber). The resulting minimum final oxygen concentration $\left(F_{\mathrm{e}}\right)$ of excurrent air was 20.00\%, measured by an Ametek S-3A one-channel oxygen analyzer. In each warm or cold run, 15-min periods of continuous $F_{\mathrm{e}}$ measurements were flanked by 1-min baseline measurements to enable accurate tracking of metabolic rate even in the event of short-term changes in baseline oxygen concentration in incurrent air $\left(F_{\mathrm{i}}\right)$. As in previous studies (Cooper and Withers 2010), sampling regime affected estimates of minimum respiration rates. Pilot studies demonstrated that, although the respirometry setup could accommodate multiple chambers from which $F_{\mathrm{e}}$ could be measured in consecutive, 
alternating cycles, measurements collected in this way were likely to miss periods of minimum metabolic rate that were detectable in data collected continuously from a single animal. Data from the thermocouple, flowmeter, and oxygen analyzer were digitally collected and displayed with Datacan software, and rates of oxygen consumption $\left(\dot{\mathrm{V}}_{2}\right)$ were computed using DAN software (both from Sable Systems).

To determine minimum metabolic rate at each temperature, we scanned each 15-min data file for the 3-min segment with the highest mean $F_{\mathrm{e}}$ (which corresponds to the lowest rate of oxygen consumption). To ensure that this 3-min period represented steady state resting metabolism at this temperature, only those 3-min periods with $\mathrm{SD} \leq 0.1 \mathrm{~mL} \mathrm{O}_{2} \mathrm{~g}^{-1} \mathrm{~h}^{-1}$ were used in subsequent analysis. In fewer than $10 \%$ of temperature trials, no 3-min periods meeting both criteria existed; in each of these cases, we used the 3-min period with the highest $F_{\text {e }}$ and $\mathrm{SD} \leq 0.2 \mathrm{~mL} \mathrm{O}_{2} \mathrm{~g}^{-1} \mathrm{~h}^{-1}$.

\section{Data Analysis}

In experiment 1 , a paired $t$-test was used to compare the percentage of SAT and UNSAT hamsters occupying the heated corner of the cage; in this analysis, each data pair represented one morning's data for all 20 hamsters. To determine the mean differential $T_{\mathrm{a}}$ chosen by each diet group on each night of the experiment, the mean difference in temperature between the warm and cool corners was multiplied by the percentage of animals from each diet group occupying the warm corner on that night. Because these daily means were not normally distributed within each diet group, we report the medians of these mean differential $T_{\mathrm{a}}$ 's chosen for each diet group and use a Wilcoxon rank sum test to compare the mean differentials between the two diet groups. In addition, percentage heated corner choice for each diet treatment group was regressed against the average coolest corner temperature to test for interactions between temperature and diet.

To determine the effect of diet on the metabolic response of hamsters to $T_{a}$, a repeated-measures analysis of variance (rANOVA) was constructed using the MANOVA personality and temperature as the repeated measure, with total $\dot{\mathrm{V}}_{2}$ or mass-specific $\dot{\mathrm{V}}_{2}\left(\dot{\mathrm{V}}_{2} / \mathrm{g}\right)$ as the response variable and diet, body mass, and a body mass $x$ diet interaction as effects. Body mass of animals in the two diet treatment groups was compared with a two-sample (unpaired) $t$-test.

The lower bound of the thermal neutral zone (lower critical temperature [LCT]) was determined individually for each animal by determining the break point between the straight lines relating $\dot{\mathrm{V}}_{2}$ to $T_{\mathrm{a}}$ within the thermal neutral zone (at $T_{\mathrm{a}}$ above the LCT) and at $T_{\mathrm{a}}$ below the LCT. Least squares analysis was used to determine the intercept, slope, change in slope at the break point, and standard deviation that minimized the sum of squares for the lines on each side of a possible break point. Break points of animals in the two diet treatment groups were then compared with a two-sample $t$-test that assumes unequal variances (included in the JMP ANOVA platform), because a transformation yielding a data set that met the assumptions of both normality and homoscedasticity could not be found.

In experiment 2, five animals (two SAT and three UNSAT) were each tested at only the four highest temperatures or the three lowest temperatures. $\dot{\mathrm{V}}_{2}$ data from these animals could not be used for break point analysis but were included in ANOVA and regression analyses.

All statistical analyses were performed with JMP (ver. 6.0.3, SAS). For statistical analyses, $\alpha$ was set at 0.05 , except for cases in which a Bonferroni correction was applied. Data are presented as mean \pm SD for normally distributed data or as median and interquartile range (IQR) for nonnormal data.

\section{Results}

\section{Experiment 1: Effect of Dietary Lipid on Temperature Choice}

Thermal choice was recorded on a total of $26 \mathrm{~d}$ for 20 hamsters, yielding a total of 520 hamster-days of thermal choice data. In each case, the hamster was found resting in a corner of the cage. The average difference between the heated corner and the coolest corner was $2.7^{\circ} \pm 0.8^{\circ} \mathrm{C}$. As $T_{\mathrm{a}}$ in the temperaturecontrolled chamber increased, the difference between the coolest corner and the warmest corner in the cage decreased, ranging from a $4^{\circ} \mathrm{C}$ average difference at $T_{\mathrm{a}}=23.5^{\circ} \mathrm{C}$ to a $2^{\circ} \mathrm{C}$ average difference at $T_{\mathrm{a}}=27.5^{\circ} \mathrm{C}$.

SAT hamsters displayed a significantly stronger preference for the heated corner $(43.5 \% \pm 20.6 \%$ over all hamster-days $)$ than did UNSAT hamsters $\left(28.8 \% \pm 27.5 \% ; t_{\text {paired }}=3.994\right.$, $\mathrm{df}=25, P=0.0005$; fig. 2). For $T_{\mathrm{a}}$ 's above $25^{\circ} \mathrm{C}$, this difference in preference for the warm corner resulted in SAT hamsters choosing a mean differential $T_{\mathrm{a}}$ (median $0.81^{\circ} \mathrm{C}$ above $T_{\mathrm{a}}$, IQR $0.57^{\circ}-1.19^{\circ} \mathrm{C}$ above $T_{\mathrm{a}}$ ) significantly higher than the mean differential chosen by UNSAT hamsters (median $0.32^{\circ} \mathrm{C}$ above $T_{\mathrm{a}}$, IQR $0.23^{\circ}-0.48^{\circ} \mathrm{C}$ above $\left.T_{a} ; Z_{\text {Wilcoxon }}=3.80, P=0.0001\right)$. Regression analysis confirmed the effect of diet $(P=0.0003)$ on temperature choice but also showed that $T_{\mathrm{a}}$ had an effect $(P<0.0001)$ on heated corner choice; at lower temperatures, hamsters of both diet treatments increased their preference for the heated corner, as would be expected when $T_{\mathrm{a}}$ falls below the lower critical temperature. In addition, as $T_{\mathrm{a}}$ increased, the difference between the percentage of SAT and UNSAT hamsters choosing the heated corner grew significantly greater, with a progressively higher percentage of SAT hamsters than UNSAT hamsters choosing the heated corner $\left(R^{2}=0.21, P=0.02\right)$.

\section{Experiment 2: Effect of Dietary Lipid on Rates} of Oxygen Consumption

Because there was no significant difference between the mass of SAT $(47.3 \pm 6.1 \mathrm{~g})$ and UNSAT $\left(45.7 \pm 6.8 \mathrm{~g} ; t_{17}=0.5\right.$, $P=0.6$; fig. 3) hamsters, animals from the two diet treatment groups were combined for all regression analyses. As expected, there was an overall significant and positive effect of log body mass on $\log$ whole-body $\dot{\mathrm{VO}}_{2}$ (rANOVA, $F_{1,15}=78.9, P<$ 0.0001 ), and separate regressions for each temperature were significant at all $T_{\mathrm{a}}$ 's $(P \leq 0.005$ in six cases; Bonferroni- 


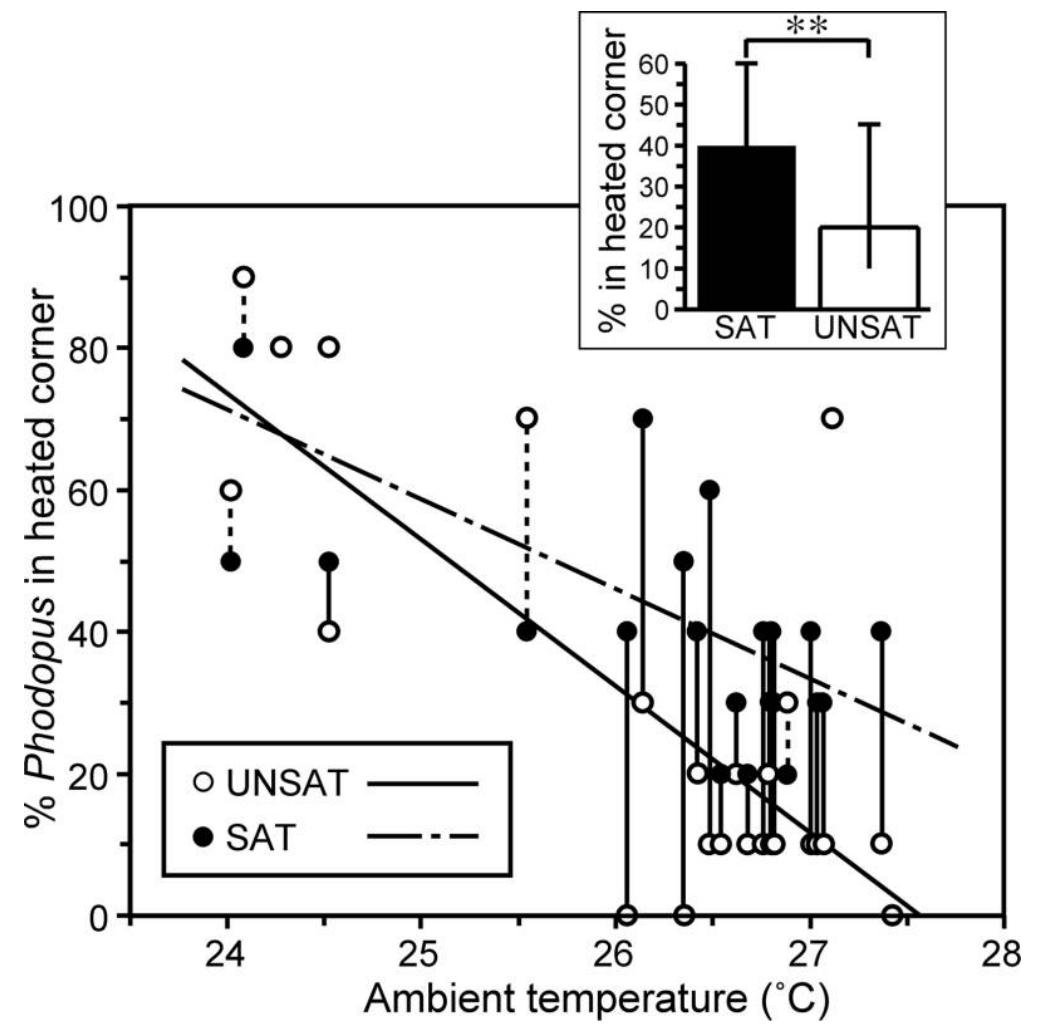

Figure 2. Experiment 1: percentage of hamsters (Phodopus sungorus) fed a diet rich in saturated fatty acids (SAT, $N=10)$ and hamsters fed a diet rich in unsaturated fatty acids (UNSAT, $N=10$ ) that chose the heated corner of the cage (rather than any of the three unheated corners) as a sleeping location on each day of the experiment as ambient temperature ( $T_{\mathrm{a}}=$ the average of the minimum corner temperatures in five similar but unoccupied cages) varied in the range within and near the thermal neutral zone (paired $t$-test, $P=0.0003$ ). Each pair of points connected by a vertical line represents the data from the two diet groups on one day of the experiment; pairs of points connected by a solid line represent data that match the prediction that a greater percentage of SAT animals than UNSAT animals should choose the heated corner, whereas pairs of points connected by a dotted line represent data that contradict this prediction. Points not connected by a vertical line represent days on which the percentages of animals in the heated corner were the same for both diet treatment groups. Regression lines are shown for the SAT group $\left(y=365.5-12.3 x, R^{2}=0.41, P=0.0004\right)$ and the UNSAT group $\left(y=549.7-19.9 x, R^{2}=0.60, P<0.0001\right)$. Inset, median (and interquartile range) percentage of animals from each diet treatment group occupying the heated corner over all nights of the experiment. Because the distributions for the two treatment groups were not normal, a nonparametric test was used for the comparison shown in the inset. Two asterisks, Wilcoxon, $P=0.005$.

corrected $\alpha=0.007)$ except $20^{\circ} \mathrm{C}(P=0.026)$. The slopes of the relations of $\log$ whole-body $\dot{\mathrm{V}}_{2}$ to $\log$ body mass at each $T_{\mathrm{a}}$ ranged from 0.63 to 1.06 (mean 0.89 ). However, there was no significant effect of diet on $\dot{\mathrm{VO}}_{2}$ (fig. 4) when it was considered either independently (rANOVA, $F_{1,15}=0.49, P=0.49$ ) or in an interaction effect with $T_{\mathrm{a}}$ (rANOVA, $F_{6,10}=1.16$, $P=0.40)$.

Overall, mass-specific $\dot{\mathrm{V}}_{2}$ was not significantly affected by diet (rANOVA, $F_{1,15}=0.14, P=0.7$; fig. 4). Log mass-specific $\dot{\mathrm{V}}_{2}$ was not significantly influenced by $\log$ body mass (rANOVA, $F_{1,15}=1.38, P=0.26$ ). Separate regressions for each temperature showed a significant negative relationship between $\log$ body mass and $\log$ mass-specific $\dot{\mathrm{V}}_{2}$ only at $28^{\circ} \mathrm{C}$ $(P=0.03$; slope $=0.33)$; at all other temperatures there was no significant relationship between these two variables $(P>$ 0.2 in all cases). In addition, there were no interaction effects between $T_{\mathrm{a}}$ and body mass (rANOVA, $F_{6,10}=0.9, P=0.5$ ) or between diet and $T_{\mathrm{a}}\left(F_{6,10}=1.17, P=0.4\right)$.
LCT break points of SAT hamsters were significantly more variable than those of UNSAT hamsters ( $F$-test, $F_{9,9}=5.09$, $P=0.024)$. Mean LCT break points were higher in UNSAT hamsters $\left(23.4^{\circ} \pm 2.7^{\circ} \mathrm{C}\right)$ than in SAT hamsters $\left(19.5^{\circ} \pm\right.$ $\left.5.5^{\circ} \mathrm{C}\right)$, but this difference did not achieve significance ( $\left.t_{\text {unequal variances }}=2.02, P=0.0650\right)$. The 24 -h mean $T_{\mathrm{b}}$ for this species, $36.6^{\circ} \mathrm{C}$ (E.C. Leininger, T. Tran, A. Veradrdo, J. Song, and S.M. Hiebert, unpublished data), falls within the $95 \%$ confidence interval of the regression line defined by wholebody $\dot{\mathrm{V}}_{2}$ at $T_{\mathrm{a}}$ below the calculated LCT break point.

\section{Discussion}

When given a choice of thermal environments, Phodopus fed a diet rich in SFAs (SAT) had a significantly greater preference for the heated corner of the cage than did hamsters fed a diet rich in PUFAs (UNSAT; fig. 2). This effect was most evident at $T_{\mathrm{a}}>26^{\circ} \mathrm{C}$, conditions in which the temperature of both the 


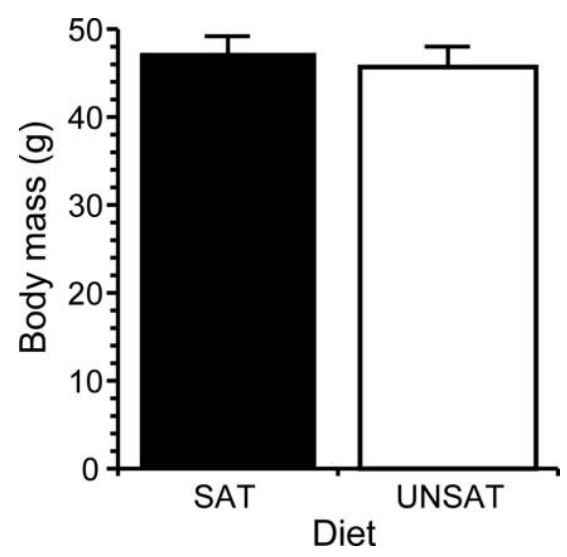

Figure 3. Experiment 2: body masses (mean \pm SEM) of Phodopus during measurements of metabolic rate, after feeding ad lib. on a coconutoil-based diet rich in saturated fatty acids (SAT) or a sunflower-oilbased diet rich in polyunsaturated fatty acids (UNSAT) for 5-7 mo. There was no significant effect of diet on body mass $(P=0.6)$.

heated and unheated corners of the cage were within the thermal neutral zone (Heldmaier and Steinlechner 1981; this study, see below). At lower $T_{\mathrm{a}}$ 's, there was a significant increase in warm corner occupancy overall; this result would be expected if $T_{\mathrm{a}}$ is below the LCT (i.e., $T_{\mathrm{a}}$ imposes a requirement for a thermoregulatory increase in energy expenditure), and heat balance could be achieved with less energy expenditure by gaining heat from an external source or at least reducing the rate of heat loss to the environment than by generating heat metabolically. In addition, the difference in thermal preference between the two diet groups narrowed as $T_{\mathrm{a}}$ decreased, converging at a $T_{\mathrm{a}}$ of $\sim 24^{\circ} \mathrm{C}$. Although extrapolation from the currently available temperature range to $T_{\mathrm{a}}<\mathrm{LCT}$ suggests that UNSAT hamsters would have a higher preference than SAT hamsters for a warm microclimate at $T_{\mathrm{a}}<24^{\circ} \mathrm{C}$, testing hamsters at these temperatures would be necessary to verify that such a relation actually exists. An important general conclusion is that dietdependent temperature selection can occur even in animals that are not expressing torpor, just as temperature-dependent diet selection occurs in continuously normothermic animals (Hiebert et al. 2000, 2003).

For the range of temperatures tested, diet-dependent thermal environment selection in Phodopus occurred in response to temperature differentials that are similar to those found in behaviorally thermoregulating lizards fed diets rich in either PUFAs or SFAs (Geiser and Learmonth 1994; Simandle et al. 2001). In the ectothermic lizard, the ability to position itself in a thermal gradient resulted in a significantly higher selected $T_{\mathrm{b}}$ in the SFA-rich diet group relative to the PUFA-rich diet group. The differences in average selected $T_{\mathrm{b}}$ between the SFArich and PUFA-rich diet groups $\left(1.3^{\circ}-3.4^{\circ} \mathrm{C}\right.$ in the study by Geiser and Learmonth [1994]) were in the same range as the average increase in $T_{\mathrm{a}}$ offered by the heated corner relative to the unheated corners of the cage $\left(2.7^{\circ} \mathrm{C}\right)$ in our study. As would be predicted by the HVA hypothesis, the diets used by Simandle et al. (2001), which differed principally in the much higher SFA : UFA ratio in the SFA-rich diet made with hydrogenated coconut oil, resulted in a slightly larger average difference in selected $T_{\mathrm{b}}\left(3.4^{\circ} \mathrm{C}\right)$. The $T_{\mathrm{a}}$ differential actually selected by the hamsters in our study (mean $0.64^{\circ} \mathrm{C}$ for all animals) was lower than the mean $T_{\mathrm{a}}$ differential available $\left(2.7^{\circ} \mathrm{C}\right)$, but the effect of diet on the actual chosen differential remains highly significant in the same direction as found in the lizard studies. Our results are consistent with a hypothesized increase in the body
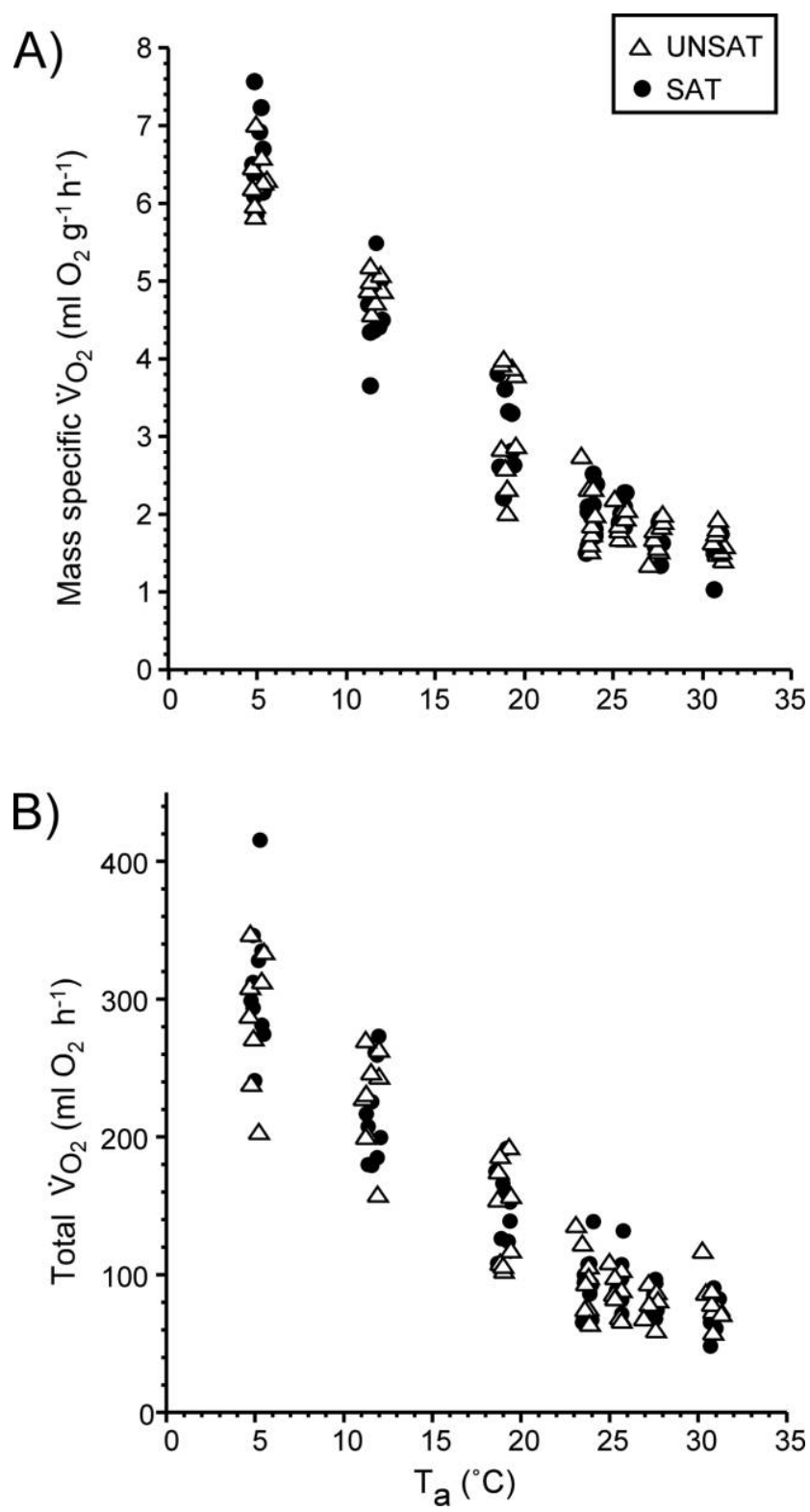

Figure 4. Experiment 2: mass-specific $(A)$ and total $(B)$ rates of oxygen consumption $\left(\dot{\mathrm{V}}_{2}\right)$ in Phodopus that had fed ad lib. on a coconutoil-based diet rich in saturated fatty acids (SAT, $N=10$ ) or a sunflower-oil-based diet rich in polyunsaturated fatty acids (UNSAT, $N=10$ ) for 5-7 mo. Where points are not visible, they are obscured by clusters of other points. There was no significant effect of diet $(P=0.7)$ or of diet $\times T_{\mathrm{a}}(P=0.4)$ on $\dot{\mathrm{V}}_{2}$. 
temperature set points of hamsters in the SFA-rich diet group relative to the PUFA-rich diet group. However, because core $T_{\mathrm{b}}$ was not measured in this study, we are unable to draw conclusions about the physiological mechanism underlying the tendency of hamsters consuming a more saturated diet to select a warmer microclimate.

Measurements of resting metabolic rate at a range of temperatures both below and within the thermal neutral zone of Phodopus did not reveal any significant differences related to the lipid composition of the diet and thus are not consistent with the notion that generally increased unsaturation index or decreased SFA: UFA ratio in membrane phospholipids increases resting metabolic rate ("membrane pacemaker" hypothesis; Hulbert and Else 1999). However, it should be noted that the evidence supporting the membrane pacemaker hypothesis comes mainly from a comparison of membrane composition on the basis not of overall PUFA content but specifically of n-3 PUFA content, principally docosohexaenoic acid (DHA; 22:6). In our study, on the other hand, dietary PUFAs in the UNSAT diet comprised principally linoleic acid (18:2; $\mathrm{n}-6)$ in combination with a much smaller fraction of $\alpha$-linolenic acid (18:3; n-3). Nevertheless, our findings concur with those of Valencak and Ruf (2007), who found no effect of n-3 PUFAs on metabolic rate across 42 species of mammals.

Mean LCTs for the UNSAT and SAT treatment groups $\left(23.4^{\circ}\right.$ and $19.5^{\circ} \mathrm{C}$, respectively) were similar to the lower end of the range of LCTs measured for Phodopus fed standard 5\% fat chow $\left(26^{\circ}-27^{\circ} \mathrm{C}\right.$ in summer and $20^{\circ}-21^{\circ} \mathrm{C}$ in winter; Heldmaier and Steinlechner 1981). Although the higher mean LCT calculated for UNSAT hamsters than for SAT hamsters in our study did not quite reach significance, we cannot rule out the possibility that a significant difference would have emerged if we had tested a larger sample size. Such a result would run counter to the prediction of the membrane pacemaker hypothesis that a higher unsaturation index should increase metabolic rate and reduce preference for a warm environment. It would, however, be consistent with the known role of unsaturated fatty acids, particularly the PUFAs highly represented in the UNSAT diet, in serving as precursors to prostaglandins (principally $\mathrm{PGE}_{2}$ ) that increase body temperature set point, as during a fever (Khanapure et al. 2007; Pecchi et al. 2009). Measurements of core body temperature, which are not available for this study, would be necessary to evaluate this hypothesis.

Overall, the results of all studies on lipid-dependent temperature selection in both endotherms and ectotherms are most consistent with the interpretation that selected tissue temperature and the SFA : UFA ratio are positively related and consistent with the hypothesis that increasing the SFA : UFA ratio in the diet and consequently in somatic tissues stimulates mechanisms that raise the temperature of these tissues to restore optimal membrane viscosity and function. Although the unsaturation index of some tissues is more resistant to remodeling (e.g., the brain, which in endotherms is also thermally one of the most well-controlled tissues, but see also Chung et al. 2008; Su 2010; Boucher et al. 2011), the unsaturation index of other tissues tends to be shifted in correlation with the unsaturation index of the diet (e.g., McMurchie 1988; Field et al. 1990; Charnock et al. 1992; Ayre and Hulbert 1996; Summers et al. 2000; Hulbert et al. 2005), as has been previously demonstrated in this species (Geiser and Heldmaier 1995). If HVA or HPA is in fact operating, it is these latter tissues that are most likely to be involved in FA remodeling and most likely to drive wholeanimal physiological and behavioral responses needed to maintain HVA or HPA. Conclusively demonstrating that HVA considerations dictate thermal choice in animals consuming diets of different unsaturation indices would require experimental manipulation and measurement of membrane fluidity itself. This approach, however, has not been used in most of the experiments that have demonstrated a relationship between dietary lipid saturation and thermoregulation in normothermic or torpid animals.

Previous experiments have shown that, when daily heterotherms are given the opportunity to make behavioral selections, they are able to respond to changes in temperature by altering their self-selected diet (Hiebert et al. 2000, 2003) and to respond to changes in the saturation of the diet by altering the selection of a thermal environment (this study). It seems likely that behavioral (and presumably physiological) mechanisms should be deployed in a complementary fashion to make use of whatever options are available in the environment. Finally, even though temperature-dependent diet selection and lipid-dependent temperature selection have been demonstrated in normothermic animals, all species tested thus far are capable of heterothermy. Repeating these experiments with obligate homeotherms would provide a better sense of whether these responses can be generalized to all endotherms.

\section{Acknowledgments}

We wish to thank Helen Leitner and Catherine Salussolia, who helped to conduct a pilot study that tested the methods used in the thermal choice experiment; Elliot Burch, who built the temperature rheostat; Marty Schultz, whose expert technical assistance was critical to the successful operation of the respirometry apparatus; Steve Wang for advice on statistics and graphical presentation of results; Phil Everson for designing and computing the likelihood function for the break point analysis; John Gerlach for animal care; Ryan Esquejo for cheerful and steadfast assistance at both Swarthmore College and Widener University; and three anonymous reviewers for their helpful comments on an earlier draft. Funding was provided by Swarthmore College, Widener University, and the University of the South. A preliminary analysis of some of these results was presented at the annual meeting of the Society for Integrative and Comparative Biology in 2003.

\section{Literature Cited}

Aloia R.C. 1988. Lipids, fluidity and functional studies of the membranes of hibernating mammals. Pp. 1-39 in R.C. Aloia, 
C.C. Curtain, and L.M. Gordon, eds. Physiological regulation of membrane fluidity. Liss, New York.

Ayre K.J. and A.J. Hulbert. 1996. Dietary fatty acid profile influences the composition of skeletal muscle phospholipids in rats. J Nutr 126:653-662.

$\rightarrow$ Boucher O., M.J. Burden, G. Muckle, D. Saint-Amour, P. Ayotte, E. Dewailly, C.A. Nelson, S.W. Jacobson, and J.L. Jacobson. 2011. Neurophysiologic and neurobehavioral evidence of beneficial effects of prenatal omega-3 fatty acid intake on memory function at school age. Am J Clin Nutr 93:1025-1037.

$\rightarrow$ Brand M.D., N. Turner, A. Ocloo, P.L. Else, and A.J. Hulbert. 2003. Proton conductance and fatty acyl composition of liver mitochondria correlates with body mass in birds. Biochen J 376:741-748.

$\rightarrow$ Brookes P.S., J.A. Buckingham, A.M. Tenreiro, A.J. Hulbert, and M.D. Brand. 1998. The proton permeability of the inner membrane of liver mitochondria from ectothermic and endothermic vertebrates and from obese rats: correlations with standard metabolic rate and phospholipid fatty acid composition. Comp Biochem Physiol B 119:325-334.

$\rightarrow$ Charnock J.S., M.Y. Abeywardena, V.M. Poletti, and P.L McLennan. 1992. Differences in fatty-acid composition of various tissues of the marmoset monkey (Callithrix jacchus) after different lipid supplemented diets. Comp Biochem Physiol A 101:387-393.

$\rightarrow$ Chung W.L., J.J. Chen, and H.M. Su. 2008. Fish oil supplementation of control and (n-3) fatty acid-deficient male rats enhances reference and working memory performance and increases brain regional docosahexaenoic acid levels. J Nutr 138:1165-1171.

$\rightarrow$ Cole G.M., Q.L. Ma, and S.A. Frautschy. 2010. Dietary fatty acids and the aging brain. Nutr Res Rev 68:S102-S111.

$\rightarrow$ Cooper C.E. and P.C. Withers. 2010. Effect of sampling regime on estimation of basal metabolic rate and standard evaporative water loss using flow-through respirometry. Physiol Biochem Zool 83:385-393.

$\rightarrow$ Dauncey M.J. and R.J. Bicknell. 1999. Nutrition and neurodevelopment: mechanisms of developmental dysfunction and disease in later life. Nutr Res Rev 12:231-253.

$\rightarrow$ Deutschlander M.E., M.J. Freake, S.C. Borland, J.B. Phillips, R.C. Madden, L.E. Anderson, and B.W. Wilson. 2003. Learned magnetic compass orientation by the Siberian hamster, Phodopus sungorus. Anim Behav 65:779-786.

Field C.J., E.A. Ryan, A.B.R. Thomson, and M.T. Clandinin. 1990. Diet fat composition alters membrane phospholipid composition, insulin binding, and glucose metabolism in adipocytes from control and diabetic animals. J Biol Chem 265:11143-11150.

$\rightarrow$ Frank C.L. and K.B. Storey. 1995. The optimal depot fat composition for hibernation by golden-mantled ground squirrel: (Spermophilus lateralis). J Comp Physiol B 164:536-542.

$\rightarrow$ Gaskill B.N., S.A. Rohr, E.A. Pajor, J.R. Lucas, and J.P. Garner. 2009. Some like it hot: mouse temperature preferences in laboratory housing. Appl Anim Behav Sci 116:279-285.

$\rightarrow$ Geiser F. and G. Heldmaier. 1995. The impact of dietary fats, $\rightarrow$ photoperiod, temperature and season on morphological variables, torpor patterns, and brown adipose tissue fatty acid composition of hamsters, Phodopus sungorus. J Comp Physiol B 165:406-415.

$\rightarrow$ Geiser F. and R.D. Learmonth. 1994. Dietary fats, selected body temperature and tissue fatty acid composition of agamid lizards (Amphibolurus nuchalis). J Comp Physiol B 164:5561.

Gunstone F.D. 1996. Fatty acid and lipid chemistry. Springer, New York.

$\rightarrow$ Hazel J.R. 1995. Thermal adaptation in biological membranes: is homeoviscous adaptation the explanation? Annu Rev Physiol 57:19-42.

$\rightarrow$ Hazel J.R. and E.E. Williams. 1990. The role of alterations in membrane lipid-composition in enabling physiological adaptation of organisms to their physical environment. Prog Lipid Res 29:167-227.

Heldmaier G. and S. Steinlechner. 1981. Seasonal control of energy requirements for thermoregulation in the Djungarian hamster (Phodopus sungorus), living in natural photoperiod. J Comp Physiol 142:429-437.

Hiebert S.M., E.K. Fulkerson, K. Lindermayer, and S. McClure. 2000. Effect of temperature on preference for dietary unsaturated fatty acids in the Djungarian hamster (Phodopus sungorus). Can J Zool 78:1361-1368.

$\rightarrow$ Hiebert S.M., K. Hauser, and A.J. Ebrahim. 2003. Djungarian hamsters exhibit temperature-dependent dietary fat choice in long days. Physiol Biochem Zool 76:850-857.

$\rightarrow$ Hulbert A.J. and P.L. Else. 1999. Membranes as possible pacemakers of metabolism. J Theor Biol 199:257-274.

$\rightarrow$ Hulbert A.J., N. Turner, L.H. Storlien, and P.L. Else. 2005. Dietary fats and membrane function: implications for metabolism and disease. Biol Rev Camb Philos Soc 80:155-169.

$\rightarrow$ Irving L., K. Schmidt-Nielsen, and N.S.B. Abrahamsen. 1957. On the melting point of animal fats in cold climates. Physiol Zool 30:93-105.

$\rightarrow$ Kariyazono H. and K. Nakamura. 2010. Pleiotropic effects of dietary fatty acids and fatty acid involvement in chronic mild inflammation-related diseases. J Health Sci 56:473-487.

$\rightarrow$ Khanapure S.P., D.S. Garvey, D.R. Janero, and L.G. Letts. 2007. Eicosanoids in inflammation: biosynthesis, pharmacology, and therapeutic frontiers. Curr Top Med Chem 7:311-340.

MacLennan M. and D.W.L. Ma. 2010. Role of dietary fatty acids in mammary gland development and breast cancer. Breast Cancer Res 12:211, doi:10.1186/bcr2646.

McMurchie E.J. 1988. Dietary lipids and the regulation of membrane fluidity and function. Pp. 189-237 in R.C. Aloia, ed. Physiological regulation of membrane fluidity. Liss, New York.

$\rightarrow$ Munro D. and D.W. Thomas. 2004. The role of polyunsaturated fatty acids in the expression of torpor by mammals: a review. Zoology 107:29-48.

National Research Council. 1996. Guide for the care and use of laboratory animals. National Academies, Washington, DC. Pecchi E., M. Dallaporta, A. Jean, S. Thirlon, and J.D. Troadec. 
2009. Prostaglandins and sickness behavior: old story, new insights. Physiol Behav 97:279-292.

Porter R.K., A.J. Hulbert, and M.D. Brand. 1996. Allometry of mitochondrial proton leak: influence of membrane surface area and fatty acid composition. Am J Physiol 271:R1550R1560.

Ruby N.F. and I. Zucker. 1992. Daily torpor in the absence of the suprachiasmatic nucleus in Siberian hamsters. Am J Physiol 263:R353-R362.

$\rightarrow$ Simandle E.T., R.E. Espinoza, K.E. Nussear, and C.R. Tracy. 2001. Lizards, lipids, and dietary links to animal function Physiol Biochem Zool 74:625-640.

$\rightarrow$ Sinensky M. 1974. Homeoviscous adaptation-homeostatic process that regulates viscosity of membrane lipids in Escherichia coli. Proc Natl Acad Sci USA 71:522-525.

Steinlechner S., G. Heldmaier, C. Weber, and T. Ruf. 1986. Role of photoperiod: pineal gland interaction in torpor control. Pp. 301-308 in H.C. Heller, L.C.H. Wang, and X.J. Musacchia, eds. Living in the cold: physiological and biochemical adaptations. Elsevier, New York.

$\rightarrow$ Su H.M. 2010. Mechanisms of n-3 fatty acid-mediated devel opment and maintenance of learning and memory performance. J Nutr Biochem 21:364-373.
Summers L.K.M., S.C. Barnes, B.A. Fielding, C. Beysen, V. Ilic, S.M. Humphreys, and K.N. Frayn. 2000. Uptake of individual fatty acids into adipose tissue in relation to their presence in the diet. Am J Clin Nutr 71:1470-1477.

$\rightarrow$ Terrien J., M. Perret, and F. Aujard. 2010. Gender markedly modulates behavioral thermoregulation in a non-human primate species, the mouse lemur (Microcebus murinus). Physiol Behav 101:469-473.

$\rightarrow \longrightarrow$. 2011. Behavioral thermoregulation in mammals: a review. Front Biosci 16:1428-1444.

$\rightarrow$ Thorp C.R., P.K. Ram, and G.L. Florant. 1994. Diet alters metabolic rate in the yellow-bellied marmot (Marmota flaviventris) during hibernation. Physiol Zool 67:1213-1229.

$\rightarrow$ Valencak T.G. and T. Ruf. 2007. N-3 polyunsaturated fatty acids impair lifespan but have no role for metabolism. Aging Cell 6:15-25.

Williams E.E. 1998. Membrane lipids: what membrane physical properties are conserved during physiochemically-induced membrane restructuring? Am Zool 38:280-290.

$\rightarrow$ Wood L.G., H.A. Scott, M.L. Garg, and P.G. Gibson. 2009. Innate immune mechanisms linking non-esterified fatty acids and respiratory disease. Prog Lipid Res 48:27-43. 